\title{
Leadership discourses in educational settings: studying and improving them through participatory action research
}

\author{
Eleni Katsarou, Georgios Polizois and Konstantinos Sipitanos \\ University of Crete
}

\begin{abstract}
In the last twenty years the literature proposals for the educational leadership, although not characterized by epistemological homogeneity, have turned to the emphasis of its social character. Educational leadership today is perceived as a social process with the most important model proposed being the "distributed leadership".

Distributed educational leadership is a proposal that has aroused substantial interest and controversy among researchers. The work presented here adopts the priority of distributed leadership and has as a starting point that the school principal is not the only leader in the school organization and its leadership -without the substantial participation and collective effort of teachers, parents and students, who are considered potential sources of leadership- proves to be formal and/or transactional.
\end{abstract}

However, there are limited studies that have investigated how roles are co-constructed, through what, more or less effective, interactions, in distributed educational leadership. In this presentation, based on a 15-month participatory action research that takes place in an Experimental High School in Greece, we argue that Leadership can be distributed when the understandings / meanings of the principal and the school community (teachers) are identified and shared through participatory research. This presupposes the contribution of the whole school community in (a) the development of the research questions, (b) the methodology, (c) the data analysis and (d) the interpretation of the findings.

More specifically, we show -through specific examples- how critical discourse analysis (the research method we used) corresponds linguistic features with specific behaviors, social identities and social groups. The participants' agency is raised when they understand that the change in their linguistic practices can contribute in the transformation of the leadership and subsequently in the transformation of their relations 
$2^{\text {nd }}$ International Conference on Modern Research in

between the teachers in a specific school community. Finally, we argue that there is a need to shift the paradigm in the research of leadership from positivist quantitative approaches to qualitative and participative ones.

Keywords: educational leadership; distributed leadership; participatory action research; critical discourse analysis 